\title{
The Effect of Appeal Type of Advertisement on Consumer's Prosocial Behavior: Focusing on the Moderating Effect of Social Exclusion
}

\author{
메시지 소구유형이 친사회적 행동에 미치는 영향: 사회적 배제의 \\ 조절효과를 중심으로
}

Eun-Young PARK(박은영)*

Received: April 25, 2019. Revised: May 05, 2019. Accepted: June 05, 2019.

\section{Abstract}

Purpose - Previous studies on the influence of appeal types of advertising messages on pro-social behavior have shown inconsistent results. The purpose of this study is to examine whether the appeal type of advertising affects consumer's prosocial behavior. In particular, the authors investigated whether the social exclusion moderates the relationship between the appeal type of advertising and prosocial behavior.

Research design, data and Methodology - To verify the hypothesis, two experimental study were conducted. The experimental study was 2(appeal type : self-benefit vs. other-benefit) by 2(social exclusion : being ignored vs. being rejected) between-subject design. Participants were randomly assigned to one of four conditions. The experiment was conducted using a computer. First, the participants was exposed to the advertising image used in the social campaign, and then responded to questions about social behavior. The participants completed the experiment after further responding to the item for manipulation check and demographic measure. The experiment took about 10 minutes in total.

Results - In Study 1, a global warming campaign with participation intention variable, other-benefit ads rather than self-benefit ads drive consumers who feel socially rejected to be more willing and likely to participate, but consumers who feel socially ignored are more likely to participate the campaign in self-benefit ad than other-benefit ad. Study 2 replicates the findings, a child poverty relief campaign with an amount-to-donate variable: consumers who feel explicitly rejected allocate more dollars to the charity in response to other-benefit rather than self-benefit ads, but consumers who being ignored are willing to donate more money.

Conclusion - This study has theoretical contribution in that it expands existing theories by explaining the existing inconsistent results of the message appeal influence on pro-social behavior through new control variables. In addition, the results have important managerial implications, suggesting marketers should tailor their marketing message to match the consumer situation.

Keywords: Being Rejected, Being Ignored, Self-Benefit Appeal, Other-Benefit Appeal, Pro-Social Behavior.

JEL Classifications: M00, M3, M30, M31, M37.

\section{1. 서론}

기부 및 타인에 대한 도움 행동 등은 일반적으로 이타주의

* First Author, Institute for Business Research \& Education at Korea University Business School, Seoul, Korea.

E-mail: eyoung.park317@gmail.com

Q Copyright: Korean Distribution Science Association (KODISA)
This is an Open Access article distributed under the terms of the Creative Commons Attribution Non-Commercial License (https:///reativecommons.org/licenses/by-nc/4.0/) which permits unrestricted non-commercial use, distribution, and reproduction in any medium, provided the original work is properly cited.
혹은 이타적 동기에 의해 행하여진다는 것이 일반적이지만 (Batson, 1990; Dovidio, Allen, \& Schroeder, 1990), 자기 이익 에 의한 이기적 동기를 통해서도 친사회적 행동이 나타나기도 한다(Cialdini, Brown, Lewis, Luce, \& Neuberg, 1997). 친사회 적 행동과 관련된 많은 연구들이 친사회적 행동에 대한 동기 를 밝히기 위해 진행되었으며 특히 마케팅 영역에서는 이와 유사하게 친사회적 소비 상황에서 광고 메시지의 소구 유형을 통해 그 효과성을 밝히고자 하였다(Bendapudi, Singh, \& Bendapudi, 1996; Brunel \& Nelson, 2000; Fisher, Vandenbosch, \& Antia, 2008). 
본 연구 역시 친사회적 행동에 대한 메시지 소구 유형이 어 떤 조건에서 더 효과적인지를 조사하고자 한다. 사람들이 언제 친사회적 행동이 증가하는지 밝히는 것은 매우 중요하다. 최근 정부와 기업, 소비자 등 다양한 분야에서 사회적 지원과 관심 이 증가하는 추세임에도 불구하고, 기부 등과 같은 친사회적 행동은 단편적이고 일시적인 지원보다는 꾸준하고 일관되게 지속되어야 하기 때문이다. 따라서 정부 및 비영리기관과 같은 캠페인의 주최기관은 사람들의 지속적인 지원과 관심을 얻기 위해 가장 효과적인 방법을 찾고자 노력하고 있다. 실제로 소 비자의 자선활동 참여를 증가시키기 위해 기업은 다양한 마케 팅 기법을 적용하고 있으며, 그 예로 타인 이익 소구(Fisher et al., 2008; Griskevicius, Van den Bergh, \& Tybur, 2010; Pessemier, Bemmaor, \& Hanssens, 1977; Peattie \& Crane, 2005; Webb, Mohr, \& Harris, 2008), 자기 이익 소구(Holmes, Miller, \& Lerner, 2002; Luchs, Naylor, Irwin, \& Raghunathan, 2010; Peattie, 2001), 혹은 둘 다 강조한 소구(Taylor \& Peter, 1995) 등 다양한 메시지 소구 유형을 활용하고 있다.

본 연구는 자선 모금 활동이나 기부 등과 같은 친사회적 행 동을 소비자에게 요청하는 광고의 설득력을 높이기 위해 실무 자들이 메시지 소구유형과 함께 고려해야하는 새로운 요인으 로 사회적 배제(social exclusion)를 제안하고자 한다. 사회적 배제는 직장이나 학교 생활에서 친구 및 동료들에게 무시 당 하거나, 데이트를 거절당하거나, 클럽 회원 자격 신청에서 거 부되는 등 사회 생활의 많은 분야에서 발생할 수 있다. 특히 명품이나 고가 브랜드의 매장에서 점원에게 은근한 무시를 당 하거나, 특정 레스토랑에서 입장을 거부 당하는 등 소비자로서 소비상황에서 겪는 사회적 배제 역시 빈번히 경험할 수 있는 일이다. 이렇듯 마케팅 상황에서 일시적으로 겪는 사회적 배제 (무시와 거절)의 경험은 부정적 감정으로 인해 이후 제품 및 서비스에 대한 소비자의 반응에 부정적인 영향을 미칠 수 있 다(Westbrook 1980; Stephens \& Gwinner, 1998; Zeelenberg \& Pieters, 2004). 따라서 소셜 마케팅 상황에서 집단에 포함 되지 못하고 사회적으로 배제된 사람들의 반응을 살펴본 본 연구는 사회적 배제와 윤리적 소비의 관계성을 밝힌 첫 시도 로서 그 의미를 찾을 수 있다.

이 연구의 목적은 친사회적 행동을 장려하기 위한 광고 메 시지의 소구가 메시지 수신자의 사회적 배제 경험에 따라 각 기 다른 설득력을 발휘하는지 검증하기 위한 것이다. 사회적으 로 배제 된 사람들은 친사회적 행동을 요청하는 광고 캠페인 에 대해 사회적으로 포함 된 사람들과는 다르게 반응한다 (Baek, Yoon, Kim, \& Kim). 특히 본 연구는 타인에 의한 사회 적 배제 유형을 무시(ignored)와 거절(rejected)로 구분하여 진 행하였다. 무시와 거절 모두 사회적 관계에서 위협을 받는다는 점에서 유사하나 거절은 직접적인 관계의 단절을 경험하는 것 으로 즉 자신이 속해있던 집단의 구성원들에게 직접적으로 부 정적인 피드백을 받는 경험인 반면, 무시는 관계가 완전히 단 절되지는 않았지만 해당 집단 내의 암묵적으로 배제당함으로 써 자신의 존재가 약해지는 경험이라는 점에서 차이가 있다 (Son \& Lee, 2016).

본 연구는 사람들이 사회적으로 무시 또는 거절을 경험한 후, 친사회적 행동을 촉구하는 광고 캠페인에 노출이 되었을 때 어떤 유형의 메시지 소구에 더 긍정적인 반응을 보이는지 살펴보고자 한다. 먼저, 집단의 구성원에게 직접적으로 단절을 의미하는 거절을 경험한 사람들은 자기 중심에서 타인 중심으 로 관점으로 이동하며(Knowles, 2014), 타인과 관련된 사회적
행동에 더 반응하므로(Hess \& Pickett, 2010) 캠페인의 메시지 가 자기 이익소구 보다 타인 이익 소구일 때 친사회적 행동이 더 증가할 것으로 예상된다. 하지만 무시를 경험한 사람들은 약해진 자신의 존재감과 효능감을 회복시키고자 하는 동기가 강하기 때문에, 자기 중심적 관점을 강화되고(Lee \& Shrum, 2012) 그 결과 자기 이익 소구 메시지에 노출될 때 타인 이익 소구보다 친사회적 행동이 더 증가할 것으로 예상할 수 있다. 즉 광고 메시지의 소구(자기이익소구 vs. 타인 이익 소구)가 어떤 조건에서 소비자의 친사회적 행동을 더 효과적으로 향상 시키는지 사회적 배제(무시 vs. 거절)와의 상호작용을 통해 살 펴보고자 한다.

본 연구는 친사회적 행동에 대한 메시지 소구 유형의 효과 성을 조절하는 새로운 조건으로 소비자의 사회적 배제를 제안 한 첫 연구이다. 특히 친사회적 행동에 대한 메시지 소구 영향 에 대한 혼재된 기존 결과를 새로운 조절변수를 통해 설명함 으로써 기존의 이론을 확장하였다는 점에서 이론적 의미를 찾 을 수 있다. 그리고 마케팅 실행적 측면에서 실무자에게는 사 회적으로 배제되었다고 느끼는 소비자에게 친사회적 행동에 대한 긍정적인 반응을 이끌어낼 수 있는 구체적인 전략 방안 을 제공한다는 점에서 실무적 의미를 가진다. 본 연구는 다음 과 같이 구성되었다. 먼저 친사회적 행동에 대한 메시지 소구 의 영향 및 사회적 배제에 대한 선행연구를 고찰하고, 이 두 변수간의 상호작용을 예측하여 가설을 설정하였다. 이후 가설 검정을 위한 두 개의 실증연구를 바탕으로 연구결과 및 시사 점을 논의하였다.

\section{2. 선행연구 고찰}

\section{1. 친사회적 행동에 대한 메시지 소구의 영향}

메시지 소구 유형은 크게 자기 이익 소구(self-benefit)과 타 인 이익 소구(other-benefit)으로 나뉜다. 소비자에게 제공하는 제품이나 서비스에 대한 혜택에 초점을 맞춘 것을 자기 이익 소구라고 하고, 다른 사람들 혹은 사회가 받는 혜택에 초점을 맞추는 것을 타인 이익 소구라고 한다(White \& Peloza, 2009). 예를 들어, 소매점에서 고객에게 재사용이 가능한 쇼핑백 사용 을 장려하는 경우, 소비자에게 재활용 가방 하나당 할인혜택을 강조하는 경우는 자기 이익 소구이며, 환경문제 혹은 사회적 혜택을 강조한 경우는 타인 이익 소구라고 할 수 있다. Allen (1982)은 메시지 소구유형과 관련된 초기 연구로서, 자기 이익 소구와 타인 이익 소구를 직접 비교한 결과 메시지 소구 유형 에 따라 각기 다른 광고 효과가 나타남을 밝혔다. 이 후 친환 경 및 친사회적 소비에 대한 소비자의 관심이 증가하면서 광 고의 메시지 소구와 친사회적 행동에 관련된 연구들도 증가하 였다. 먼저 환경문제에 대한 관여도가 낮은 소비자의 경우 자 기 이익 소구에 호의적으로 반응하는 반면, 환경문제에 대한 관여도가 높은 소비자는 자기 이익 소구와 타인 이익 소구 모 두 동일하게 반응하는 것을 발견하였다(Taylor \& Peter, 1995).

특히 그린 제품에 대한 소비자의 반응은 타인 이익 소구 메 시지에 더 긍정적인 태도를 보였다. Webb, Mohr, and Harris (2008)은 사회적 책임 소비는 자기 중심보다는 사회 지향적임 을 밝혔고, 따라서 친환경 제품을 구매할 때 사회적 책임이 높 은 소비자는 항상 개인의 이익보다는 환경의 이익에 집중하는 
것을 보여주었다. 이와 유사하게 그린 제품의 구매를 통해서 사회에 이익이 된다면 소비자 개인의 이익을 포기할 수도 있 다는 연구결과도 존재한다(Griskevicius, Van den Bergh, \& Tybur, 2010). Peattie and Crane (2005)은 소비자 전체에게 미래의 이익을 제공하는 그린 제품은 소비자 개인의 이익만을 제공하는 그린 제품보다 제품에 대한 구매 의도를 더 효율적 으로 증가시킬 수 있음을 밝혔다. 장기 기증과 관련된 연구에 서도 역시, 금전적 인센티브 형태의 자기 이익 소구를 사용할 경우, 타인 이익 소구와 비교할 때 장기 기증의도가 유의하게 감소하였다(Pessemier, Bemmaor, \& Hanssens, 1977). 공영방 송국 기금 모금에 대한 반응 역시 자기 이익 소구보다는 타인 이익 소구에 더 긍정적이었다(Fisher et al., 2008). 이러한 연 구 결과들은 친사회적인 소비가 타인 이익과 관련될 때 더 긍 정적인 반응을 이끈다는 것을 시사한다.

이와는 대조적으로, 자기 이익을 제공하는 것이 친사회적 행동을 장려하는 데 더 적합하다는 연구들도 있다. 이러한 관 점의 연구들은 대부분의 친사회적인 행동은 이기주의에 근거 하므로(De Groot \& Steg, 2008; Stern, 2000), 자기 이익 소구 를 강조하는 것이 특히 효과적이라고 주장하였다(Mathur, 1996). 좀 더 구체적으로 살펴보면, Holmes, Miller, and Lerner (2002)는 사람들이 타인을 돕고자 하지만 도움 행동이 자기 이익과 관련해 정당화할 수 없다면 주저하게 된다고 주 장하면서, 금전적 기부는 이타적 동기 보다는 이기적인 동기에 의해 나타난다고 하였다. Peattie (2001) 역시 사람들에게 개개 인의 비용 절감을 강조할 때 친환경 소비 행동이 증가함을 보 여주었다. 이러한 결과와 유사하게, Luchs, Naylor, Irwin, and Raghunathan (2010) 또한 그린 소비 과정에서 소비자의 개인 이익이 감소하면 제품에 대한 저항감이 생겨 제품 선택에 영 향을 미친다는 사실도 발견했다. 이를 종합해보면, 소비자에게 개개인의 이익을 제공하거나 강조하는 것은 그들의 친사회적 행동을 강화시킬 수 있음을 파악할 수 있다.

선행 연구를 요약하면, 친환경 소비에 대한 소비자의 호의 적인 반응은 타인 이익일 때와 자기 이익일 때 모두 나타나며 그 결과는 혼재되어 있음을 알 수 있다. 본 연구는 어떤 조건 에서 각 유형의 메시지 소구가 소비자의 친사회적인 행동에 더 효과적인 반응을 나타내는지 살펴보고자 하며, 그 조건으로 소비자의 사회적 배제 상황에 초점을 맞추어 살펴보고자 한다.

\section{2. 사회적 배제와 소비자 반응}

사회적 배제란 정치적, 사회적, 경제적 이유로 자신이 속해 있는 집단이나 조직에서 참여가 통제되거나 차별을 당하는 것 이라고 할 수 있다(Oh \& Hwang, 2014). 인간은 사회적 동물 이며 사회적 환경 속에서 구성원들과 관계를 형성하고 소속되 어 살아가고자 하는 기본 욕구를 가지고 있다(Baumeister \& Leary, 1995). 하지만 사회적으로 소속되지 못하고 배제를 경 험하게 되는 사람들은 부정적 정서를 경험하게 되고(Buckley, Winkel, \& Leary, 2004; Williams, Cheung, \& Choi, 2000) 인 지적 정보처리의 결핍으로 인해 반사회적 행동을 나타낸다 (Baumeister, DeWall, Ciarocco, \& Twenge, 2005; Warburton, Williamsm, \& Cairns, 2006). 하지만 사회적 배제로 인해 부정 적 감정이 발생한다 할지라도 공격적이고 반사회적인 행동만 을 하는 것은 아니다. 사회적 배제가 오히려 타인에 대한 도움 행동이나 협동행동과 같은 친사회적 행동을 증가시킨다는 연 구도 존재한다(Baumeister et al. 2005; Loveland, Smeesters,
\& Mandel, 2010; Maner, Dewall, Baumeister, \& Schaller, 2007; Mead, Baumeister, Stillman, Rawn \& Vohs, 2011; Twenge, Baumeister, Tice, \& Stucke, 2001).

본 연구는 타인에 의한 사회적 배제 유형을 무시(ignored)와 거절(rejected)로 구분하여 살펴보고자 한다. 사회적 배제 경험 은 사회적 관계 맥락에서 위협을 받는다는 점에서 유사하나 거절은 직접적인 관계의 단절을 경험하는 것으로 즉 자신이 속해있던 집단의 구성원들에게 직접적으로 부정적인 피드백을 받는 경험인 반면, 무시는 관계가 완전히 단절되지는 않았지만 배제의 이유에 대해 정확한 피드백을 받지 못하고 암묵적으로 타인이나 사회로부터 배제당하는 경험이라는 점에서 차이가 있다(Lee \& Shrum, 2012; Molden et al., 2009).

선행연구에 따르면, 무시를 경험한 사람은 자신이 느끼는 해당 집단 내에서 자신의 존재가 약해짐으로써 자신의 존재감 과 효능감을 위협받게 되고, 결국 약화된 자신의 존재감과 효 능감을 회복시키고자 조직 내에서 더욱 더 자신의 존재감을 부각시키는 소비를 하게 된다(Lee \& Shrum, 2012). 반면 거절 을 경험하게 되면 단절된 관계에 대해 위협을 느끼게 되고, 향 후 사회적 관계를 재연결(social reconnection)시키고자 다른 사람들의 행동을 모방하거나, 친사회적 행동을 한다(Lakin, Chartrand, \& Arkin, 2008; Mead, Baumeister, Stillman, Rawn, \& Vohs, 2011; Lee \& Shrum, 2012).

이렇듯 사회적 배제 경험에 따라 서로 다른 행동 반응을 보 이는 이유는 사회적 배제를 통해 느끼는 욕구의 차이와 감정 의 차이 때문이다. 먼저 Lee and Shrum (2011)은 사회적 배 제가 관계 욕구 및 효능감 욕구와 같이 서로 다른 욕구로 인 해 다른 행동을 유도한다고 제시하였다. 반면, Debono (2011) 는 사회적 배제에 의해 사람들이 느끼는 감정의 차이에서 비 롯된다고 제시한다. 즉 화가 나면 공격적인 행동을 하게 되고 슬픔을 느끼게 되면 동정이나 연민, 사람들의 니즈에 자신을 맞추려 노력한다는 것이다(Oh, Park, \& Park, 2017). 이와 더 불어 사회적 배제로 인해 오히려 감정이 무뎌지거나 동정심에 한 감정을 스스로 철회시킴으로서 기부와 같은 친사회적 행동 이 감소되기도 한다(Dewall \& Baumeister, 2006; Twenge et al., 2003).

\section{3. 친사회적 행동에 대한 메시지 소구 유형과 사회 적 배제와의 상호작용 효과}

본 연구는 친사회적 행동에 대한 사회적 배제와 캠페인 메 시지 소구 유형과의 관계성을 살펴보고자 한다. 특히 친사회적 행동에 대한 메시지 소구 유형의 효과성은 사회적 거절 혹은 사회적 무시 경험에 의해 다른 반응이 나타날 수 있음을 제안 한다.

배가 고프면 음식 관련 자극에 대한 기억이 떠오르는 것처 럼, 소속에 대한 욕구가 불충분하면 사회적 배고픔 역시 자동 적으로 사회적 기억을 떠오르게 한다(Gardner, Pickett, \& Brewer, 2000). Gardner et al. (2000)은 실험을 통해 컴퓨터 채팅룸에서 피험자에게 acceptance 혹은 rejection을 경험하게 조작한 후, 사회적 그리고 개인적 이벤트가 포함된 일기를 읽 게 하였다. 그 결과, 사회적으로 거절을 경험한 피험자는 사회 적 이벤트가 적힌 일기를 선택적으로 더 잘 기억하였다. 즉 사 회적 거절은 사회적 재연결에 대한 욕구에 의해 사회적 측면 에 더욱 집중하려는 경향을 만들었다. 이와 유사한 선행 연구 를 살펴보면, 사회적 거절을 경험한 사람들은 자기 중심에서 
타인 중심으로 관점이 이동하였다(Knowles, 2014). 거절을 경 험한 피험자들은 인지부하(cognitive load) 조건에서 조차 통제 집단보다 사회적 협력이 요구되는 과제 수행에서 타인 중심적 인 관점을 더 나타내었다. 관점의 이동과 더불어 사회적으로 배제를 경험한 사람은 타인의 감정을 관리하려는 경향이 강해 진다. 이는 타인의 감정 관리를 통해 사회적 재연결을 증가시 키고자 하는 것이다(Cheung \& Gardner, 2015). 마지막으로 Hess and Pickett (2010)는 사회적으로 거절된 사람들은 거절 에 대한 심리적 고통으로부터 자신을 지키기 위한 방어전략으 로 자기의식(self-awareness)을 약화시킨다고 하였다. 이렇게 감소된 자기의식은 오히려 사회적 영역을 강화시켜 타인 행동 에 대한 인식을 증가시켰다. 지금까지 살펴본 바와 같이, 사회 적으로 거절을 경험한 사람들은 자기 중심보다는 타인 및 사 회 중심적 반응을 나타내는 것을 알 수 있다. 이를 바탕으로 우리는 사회적 거절 경험이 있는 사람들은 자기 중심보다는 타인 중심 메시지에 더 호의적인 반응을 나타낼 것으로 예상 할 수 있다.

이와 대조적으로, 사회적으로 무시를 경험한 사람들은 거절 을 경험한 사람과는 다르게 자기 중심적인 반응을 보여주었다. Lee and Shrum (2012)은 사회적 배제를 거절과 무시로 구분 하고 과시적 행동과 친사회적 행동에 미치는 영향을 살펴보았 다. 그 결과 무시를 경험한 피험자가 보이는 과시적 소비는 자 신에게 시선을 집중시켜 다른 사람에게 보여주기 위한 행동이 며, 자기가 누구인지 그 의미를 전달하고자 하는 자기 중심적 (self-focused) 행동이라고 설명하였다. 또한 사회적인 무시는 사회적 고립을 통해 느끼는 외로움과 유사한 감정이다(Kemp, Moore, \& Cowart, 2016). 외로움은 자기 표현에 대한 내재적 동기를 증가시키고 자기 중심성을 증가시키는 것으로 나타났 다(Cacioppo, Chen, \& Cacioppo, 2017). 또한 외로움을 경험 한 사람들은 광고의 타인지향 메시지보다 자기 중심 메시지에 더 호의적으로 반응한다는 것을 보여주었다(Kemp, Moore, \& Cowart, 2016). 따라서 사회적 무시를 경험한 사람들은 자기 중심적 행동을 보이며 따라서 자기 중심적 메시지에 더 호의 적임을 예상할 수 있다. 이와 같은 논리에 의해 다음과 같은 가설을 도출할 수 있다.

$\mathrm{H1}$ : 광고 메시지의 소구 유형과 사회적 배제 경험의 상호 작용은 소비자의 친사회적 행동에 영향을 미칠 것이 다.

H1a: 사회적 무시를 경험한 사람은 이타 이익 소구 보다 자기 이익 소구 메시지에 더 호의적인 친사회적 행 동을 보일 것이다.

$\mathrm{H1b}$ : 사회적 거절을 경험한 사람은 자기 이익 소구 보다 이타 이익 소구 메시지에 더 호의적인 친사회적 행 동을 보일 것이다.

본 연구는 가설을 검증하기 위해 두 개의 실험을 진행하였 다. 실험 1은 친사회적 행동으로 지구 온난화 예방을 위한 대 중교통 이용 캠페인을 활용하여 소비자의 참여의도를 통해 살 펴보았고, 실험 2는 아동 빈곤 구제 캠페인에 얼마나 기부할 것인지 실제 기부금액을 통해 검증하였다.

\section{3. 연구방법}

\section{1. 실험 1}

본 실험의 목적은 가설 1 에서 언급한 것과 같이 소비자의 친사회적 행동에 대한 사회적 배제 경험과 메시지 소구 유형 과 상호 작용의 영향을 검증하는 것이다. 구체적으로 실험은 지구온난화 캠페인에 대한 참여 요청 상황으로 설정하였으며, 종속변수인 친사회적 행동은 실험 상황에 맞추어 캠페인 참여 의도로 측정하였다. 본 실험을 통해 사회적으로 무시를 경험한 소비자들은 메시지 소구 유형이 이타적 소구일 때보다 이기적 소구일 때 캠페인에 참여하고자 하는 의도가 더 높아지는 반 면, 사회적으로 거절을 경험한 소비자는 자기 이익 소구보다 타인 이익 소구일 때 캠페인에 참여하고자 하는 의도가 더 높 을 것으로 예상된다.

\subsection{1. 피험자 및 설계}

서울 소재의 대학교 학부생 중 마케팅원론을 수강하는 100 명(남자 : $52 \%$ )이 본 실험의 피험자로 참가하였으며, 참가한 모든 학생에게는 extra credit을 제공하였다. 실험은 3(사회적 배제 : 무시 vs. 거절 vs. 통제) $\times 2$ (메시지 소구 유형 : 자기 이익 vs. 타인 이익)의 피험자간 설계이다.

\subsection{2. 실험절차}

실험 참가자들에게 '특정 경험에 관한 조사'와 '환경보호 캠 페인 설문조사' 이라는 관련 없는 두 가지의 설문조사에 참여 하게 될 것이며 모든 설문은 컴퓨터를 이용하여 진행될 것이 라고 소개하였다. 먼저 특정 경험에 관한 조사는 사회적 배제 경험을 조작하기 위해 실시되었다. 피험자를 무작위로 세 개의 집단 중 한 집단에 배정하였다. 선행연구에서 사회적 배제를 조작하기 위해 사용했던 방법과 동일하게, 무시 집단은 피험자 에게 살아오면서 사회적으로 암묵적 무시를 당했던 경험을, 거 절 집단은 살아오면서 사회적으로 거절(거부)을 당한 경험을 작성하도록 하였으며, 통제 집단의 피험자에게는 최근 쇼핑 경 험을 자세히 작성하도록 하였다(Knowles \& Gardner, 2008; Maner, DeWall, Baumeister, \& Schaller, 2007). 총 5분 동안 자유롭게 기술하되, 최대한 상세하게 당시 상황을 쓰도록 하였 다. 에세이 작성이 끝난 후, 피험자는 사회적 배제를 경험한 당시 얼마나 암묵적으로 무시를 당했다고 느겼는지 그리고, 얼 마나 대놓고 거절당했다고 느겼는지에 대하여 응답하였다(1= 전혀, 7=매우). 이 항목은 사회적 배제 유형에 대한 조작점검 을 위한 항목으로 분석하여 활용하였다. 첫 번째 조사가 끝난 후, 피험자들은 연구자의 지시에 따라 두 번째 설문을 시작하 였다. 연구자는 피험자에게 '지구 온난화 캠페인 설문조사'가 실제 캠페인에 사용되는 광고이미지라고 소개하고, 이 캠페인 을 잘 살펴본 후 설문에 응답하도록 하였다. 두 번째 조사도 역시 컴퓨터를 이용하여 진행되었다. 피험자들은 먼저 설문조 사의 주의사항을 읽은 후, 모니터에 나타난 지구 온난화 캠페 인을 살펴보았다. 캠페인 광고에는 지구온난화를 늦추기 위해 대중교통이나 자전거를 주로 이용하자는 참여방법과 함께, 메 시지 소구 유형을 조작하기 위한 메시지가 나타난다. 타인 이 익 소구 조건은 "당신의 작은 실천으로 지구의 미래가 건강해 집니다"라는 메시지를 제공한 반면, 자기 이익 소구 조건은 " 
당신의 작은 실천으로 당신의 미래가 건강해 집니다“라는 메 시지를 제공하였다. (<Eigure 1a>, <Figure $1 \mathrm{~b}>$ 참조).

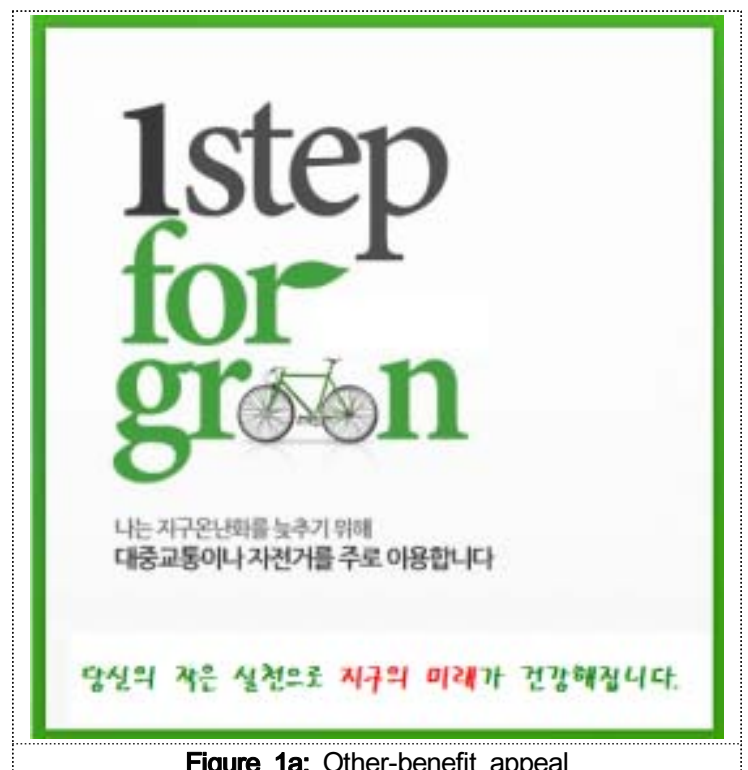

Figure 1a: Other-benefit appeal

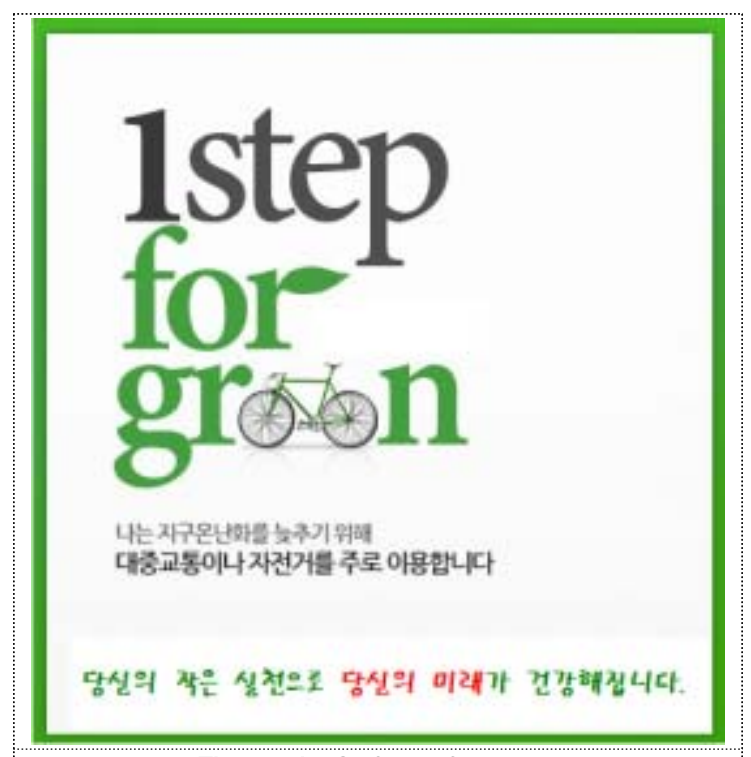

Figure 1b: Self-benefit appeal

캠페인 광고를 충분히 살펴본 실험 참가자들은 종속 변수인 캠페인 참여의도에 대해 응답하고 메시지 소구 유형에 대한 조작점검 항목에 대하여 답하였다. 먼저 참가자들은 이 캠페인 에 얼마나 참여하고 싶은지의 정도에 대하여(1=전혀 참여하고 싶지 않다, $7=$ 매우 참여하고 싶다) 응답하였다.

이후 메시지의 소구유형에 대한 조작이 성공적으로 이루어 졌는지를 살펴보기 위해 캠페인에 사용된 메시지의 소구 유형 에 대한 조작점검을 측정하였다. 이기적 소구와 이타적 소구에 대한 기존연구의 정의를 기반으로(White \& Peloza, 2009), 기 부 참여에 대한 혜택이 자기 자신에게 초점이 맞추어졌는지,
다른 사람에게 맞추어졌는지 2 개의 항목으로 측정하였다(1=전 혀 그렇지 않다. $7=$ 매우 그렇다). 마지막으로 성별 및 나이 등 인구통계학적 질문에 응답하였다. 두 개의 실험 진행에는 총 10 분 정도가 소요되었으며, 실험이 끝난 후 참가자들에게 연 구의 목적에 대한 설명을 간단히 한 후, 감사의 말과 함께 실 험을 종료하였다.

\subsection{3. 결과}

\subsubsection{1. 조작점검}

본 실험에 들어가기에 앞서, 사회적 배제 경험과 메시지 소 구 유형 두 변수의 조작이 제대로 이루어졌는지를 알아보기 위한 분석을 실시하였다. 먼저 사회적으로 배제된 경험을 구체 적으로 쓰게 한 이후, 암묵적으로 무시를 당했다고 느낀 정도 와 명시적으로 거절당했다고 느낀 정도에 대해 분석하였다. 세 조건의 피험자는 무시조건 33명, 거절 조건 33명, 그리고 통제 조건 34명으로 이루어졌다. 각 집단별 차이를 살펴본 결과, 무 시 조건의 피험자 $(\mathrm{M}=5.10)$ 들이 거절 조건 $(\mathrm{M}=4.55)$ 과 통제 조 건(M=1.68)보다 더 암묵적으로 무시당했다고 인식하였으며, 세 조건간의 차이는 통계적으로 유의하였다 $(\mathrm{F}(2,97)=50.288$, $\mathrm{p}=.000)$. 또한 거절 경험을 작성한 피험자 $(\mathrm{M}=5.15)$ 는 무시 조 건 $(\mathrm{M}=4.63)$ 과 통제조건 $(\mathrm{M}=1.50)$ 보다 명시적으로 거절당했다고 느끼는 정도가 더 높았으며, 이 차이 또한 통계적으로 유의하 였다 $(\mathrm{F}(2,96)=66.653, \mathrm{p}=.000)$.

가부 캠페인 광고의 메시지 소구에 대한 조작을 검증하고자 분석한 곁과, 자기 이익 소구 메시지에 노출된 피험자들 $(\mathrm{M}=5.91)$ 은 타인 이익 소구 메시지에 노출된 피험자 $(\mathrm{M}=4.78)$ 보다 더 캠페인 참여에 대한 혜택이 자기 자신에게 초점이 맞 추어졌다고 응답한 반면, 타인 이익 소구 메시지에 노출된 피 험자들 $(\mathrm{M}=5.34)$ 은 자기 이익 소구 조건( $\mathrm{M}=4.07)$ 보다 더 캠페 인 참여에 대한 혜택이 다른 사람에게 맞추어졌다고 응답하였 다. 두 조건간의 차이는 통계적으로 유의하였다 $(p<.05)$. 결과 적으로 두 변수에 대한 조작은 성공적이었다.

\subsubsection{2. 캠페인 참여의도에 대한 결과 분석}

우리는 앞서 제시된 가설에서 사회적으로 무시를 경험한 사 람의 경우, 자기 이익 소구의 메시지 조건이 타인 이익 소구 메시지 조건에 비해 더 호의적인 친사회적 행동을 보이는 반 면, 사회적으로 거절을 경험한 사람의 경우에는 타인 이익 소 구 메시지일 때 (vs. 자기 이익 소구) 더 호의적인 친사회적 행동을 보일 것으로 예측하였다. 이를 검증하기 위해 3(사회적 배제: 무시 vs. 거절 vs. 통제) $\times 2$ (메시지 소구 유형: 자기 이 익 vs. 타인 이익) 분산분석(ANOVA)을 실시하였다. 결과는 다 음과 같다. 먼저, 캠페인 참여 의도에 대해 메시지 소구 유형 $(\mathrm{F}(1,94)=.265, \mathrm{p}=.608)$ 과 사회적 배제 경험 유형 $(\mathrm{F}(2,94)=$ $1.810, \mathrm{p}=.169)$ 에 대한 주효과는 모두 통계적으로 유의하지 않 았다. 반면 메시지 소구 유형과 사회적 배제 경험간의 상호작 용 효과는 캠페인 참여 의도에 대해 통계적으로 유의하게 나 타났다 $(\mathrm{F}(2,94)=4.256, \mathrm{p}=.017)$. 각 조건에 해당하는 평균 값 및 표준편차는 <Table 1>과 같다. 본 연구에서 관심을 가 지고 중요하게 다루고 있는 가설 1 의 검증 여부를 알아보기 위해 사회적 배제 경험과 메시지 소구 유형 간 상호작용이 어 떠한 패턴으로 통계적 의미를 갖는지 해석하고자 캠페인 참여 의도에 대한 대비(contrast) 검정을 각각 실시하였다. 그 결과, 사회적으로 무시를 당한 경험이 있는 소비자들은 자기 이익 
소구 메시지 조건일 때가 타인 이익 소구 메시지 조건일 때보 다 기부 참여 의도가 더 높은 반면(M타인 이익 = 3.63, vs. M 자기 이익 $=4.77, \mathrm{~F}(2,94)=5.774 \mathrm{p}=.018)$, 사회적으로 거절을 당한 경험이 있는 소비자들은 타인 이익 소구 메시지 일 때가 자기 이익 소구 메시지일 때 기부 참여의도가 한계적 으로 더 높게 나타났다(M타인 이익 $=4.88, v s$. M자기 이익 $=$ 4.06, $\mathrm{F}(2,94)=2.958, \mathrm{p}=.088)$. 통제조건에서는 소구 유형 에 따른 유의한 차이가 나타나지 않았다(M타인 이익 $=4.78$ vs. $\mathrm{M}$ 자기 이익 $=4.88, \mathrm{~F}(2,94)=.043, \mathrm{p}=.836)$. 결과적으 로 사회적 배제 유형과 메시지의 소구 유형간 상호작용이 캠 페인 참여 의도에 미치는 영향에 있어 실시한 대비 검정 결과 를 종합하면 가설 1 이 부분 지지되었음을 알 수 있다.

Table 1: The interaction effect of social exclusion and appeal type of message on participation intention (study 1)

\begin{tabular}{|c|c|c|c|c|c|c|c|}
\hline \multicolumn{2}{|c|}{} & \multicolumn{4}{|c|}{ appeal type of message } & \multirow{3}{*}{ s } & \multirow{3}{*}{ P } \\
\cline { 3 - 6 } \multicolumn{2}{|c|}{} & \multicolumn{2}{|c|}{ other-benefit } & \multicolumn{2}{c|}{ self-benefit } & & \\
\cline { 2 - 6 } & $\mathbf{M}$ (S.D.) & $\mathbf{n}$ & M (S.D.) & $\mathbf{n}$ & & \\
\hline \multirow{3}{*}{$\begin{array}{c}\text { social } \\
\text { exclusion }\end{array}$} & ignore & $3.63(1.50)$ & 16 & $4.77(1.30)$ & 17 & & \\
\cline { 2 - 6 } & reject & $4.88(1.50)$ & 16 & $4.06(1.20)$ & 17 & 4.256 & .017 \\
\cline { 2 - 6 } & control & $4.78(1.31)$ & 18 & $4.88(1.36)$ & 16 & & \\
\hline
\end{tabular}

추가적으로 친사회적 행동의도에 대해 각 조건의 평균을 통 제집단과 비교해본 결과, 거절을 경험한 집단에서는 타인이익 메시지 조건에서 통제그룹과 참여의도간의 차이가 나타나지 않았고( $\mathrm{M}$ 거절=4.88 vs. $\mathrm{M}$ 통제=4.78, $\mathrm{p}>$.05), 무시를 경험한 집 단에서도 역시 자기이익 메시지에 대해 통제그룹과 차이가 나 타나지 않았다(M무시=4.77 vs. $\mathrm{M}$ 통제 $=4.88, \mathrm{p}>.05)$. 이러한 결 과들을 종합적으로 볼 때, 사회적 배제를 경험한 사람들은 부 정적 경험으로 인해 통제집단보다 친사회적 행동의도가 낮아 질 수 있다. 그럼에도 불구하고 사회적 배제에 따른 적합한 광 고 메시지 소구를 이용한다면 일반적인 수준, 즉 부정적인 사 회적 배제 경험을 하지 않은 상황과 동일한 수준까지 친사회 적 행동을 이끌어낼 수 있음을 의미한다.

\section{2. 실험 2}

실험 2의 목적은 실험 1 에서 검증한 효과를 재검증하며 일 반화하는데 주력하였다. 먼저, 실험을 실시하는 맥락을 환경보 호활동에 대한 참여 상황에서 아동 구제 기금 모금에 대한 참 여 상황으로 확대하였다. 종속 변수인 친사회적 행동 또한 기 부금액으로 측정하고 결과를 분석하였다. 더불어 본 실험에서 는 캠페인 수혜자에 대한 동정심 죄책감 등의 부정적인 감정 을 추가적으로 측정하였다. 선행연구에 따르면, 사회적 배제 경험은 긍정적 소비자의 반응을 유발시키기도 하지만 (Baumeister et al., 2005; Loveland, Smeesters, \& Mandel, 2010; Maner, Dewall, Baumeister, \& Schaller, 2007; Mead, Baumeister, Stillman, Rawn, \& Vohs 2011; Twenge, Baumeister, Tice, \& Stucke, 2001), 부정적 영향을 미치기도 한다(Baumeister, DeWall, Ciarocco, \& Twenge, 2005; Warburton, Williamsm \& Cairns, 2006). 이러한 상반된 결과들 은 사회적 배제 유형에 따른 감정의 차이에 의해 기인 (Debono, 2011; Dewall \& Baumeister, 2006; Twenge et al.,
2003) 하므로, 두 변수의 상호작용 효과가 감정에 영향을 미 치는지 그리고 더 나아가 감정에 의해 친사회적 행동이 나타 나는지 살펴볼 필요가 있다. 따라서 가설을 검증한 후, 감정에 대한 메시지 소구 유형과 사회적 배제의 영향을 추가분석 하 고자 한다.

실험 2의 결과도 역시 실험 1과 동일하게, 메시지 소구 유 형이 친사회적 행동에 미치는 영향이 소비자의 사회적 배제 경험에 의해 조절될 것을 예상할 수 있다. 즉 암묵적인 무시를 경험한 피험자들은 기부 메시지가 자기 이익 소구일 때, 타인 이익 소구일 때보다 더 많은 금액을 기부할 것이다. 반면 사회 적으로 거절을 경험한 피험자들은 자기 이익 소구보다는 타인 이익 소구일 때 기부 금액이 더 증가할 것이다. 즉 기부를 얼 마나 할 것인가에 대한 기부 금액 의사 결정 또한 실험 1 과 유사한 패턴의 결과를 나타낼 것으로 기대한다.

\subsection{1. 피험자 및 설계}

실험 2의 피험자들은 서울 소재 대학교의 경영학과 재학생 148명(남자: 84명(56.8\%))으로 실험 1과 중복되지 않으며, 실 험 참가의 대가로 extra credit을 받았다. 실험 2는 실험 1 의 통제 집단을 제외한 2(메시지 소구 유형: 자기 이익 vs. 타인 이익) $\times 2$ (사회적 배제 경험: 무시 vs. 거절)의 피험자간 설계 이다.

\subsection{2. 실험절차}

실험 2는 실험 참가자들이 보게 되는 자극물이 아프리카 어 린이에 대한 기부 캠페인으로 바뀐 것을 제외하고 실험 절차 와 설문항목 등은 실험 1과 유사하게 진행되었다. 실험 2의 참가자들 역시 먼저 '특정 경험에 관한 조사' 설문을 실시하였 고, 조작 방법은 실험 1 과 동일하게 진행되었다. 이후 '기부 캠페인 설문조사'에서는 기아를 겪는 아프리카의 아기 사진과 함께 메시지가 나타났으며, 이 메시지를 통해 메시지 소구 유 형을 조작하였다. 타인 이익 메시지 소구 조건은 "도와주세요! 여러분의 작은 도움으로 이 아이는 삶의 희망을 얻습니다“라 는 메시지를 제공한 반면, 자기 이익 메시지 소구 조건은 “도 와주세요! 아이에게 주는 작은 도움으로 여러분은 더 큰 삶의 행복을 얻습니다" 라는 메시지를 제공하였다.

아동 구제 기금모금 캠페인 광고를 충분히 살펴본 실험 참 가자들은 종속변수인 기부금액과 캠페인을 보고 느낀 감정에 대해 응답하였다. 기부금액은 응답자들이 이 기부 캠페인에 얼 마나 기부하고 싶은지의 정도를 자유롭게 기입하도록 하였다. 감정은 총 3 가지 항목(동정심, 죄책감, 부정적 감정)으로 7점 척도로 측정되었으며 $1=$ 전혀 아니다, $7=$ 매우 그렇다), 점수가 높을수록 동정심과 죄책감, 부정적 감정의 정도가 높다는 것을 의미한다. 다음으로 피험자는 메시지 소구 유형에 대한 조작점 검 항목에 대하여 답하였다. 마지막으로, 성별 및 나이 등 인 구통계학적 항목을 측정한 후, 참가자들에게 연구의 목적에 대 한 설명을 간단히 설명하고 감사의 말과 함께 실험을 종료하 였다.

\subsection{3. 결과 및 토의}

\subsubsection{1. 조작 점검}

실험 1과 마찬가지로 사회적 배제 경험과 메시지 소구 유형 두 변수에 대한 조작 점검에 대한 분석을 실시하였다. 그 결 
과, 무시 조건의 피험자들이 거절 조건보다 더 암묵적으로 무 시당했다고 인식하였으며, 거절 조건의 피험자는 무시 조건보 다 명시적으로 거절당했다고 느끼는 정도가 더 높았으며, 두 조건간의 차이는 통계적으로 유의하였다 $(\mathrm{p}<.05)$. 기부 캠페 인 광고의 메시지 소구에 대한 조작 점검 역시 실험 1 의 결과 와 동일하였고, 결과적으로 두 변수에 대한 조작은 성공적이었 다.

\subsubsection{2. 기부금액에 대한 결과 분석}

가설 1 에서 제안한 메시지 소구 유형과 소비자의 사회적 배 제 경험이 기부 금액에 미치는 영향력을 분석하기 위해 2(메 시지 소구 유형 : 타인 이익 vs. 자기 이익) $\times 2$ (사회적 배제 경험: 무시 vs. 거절) ANOVA를 실시하였다. 그 결과 예상되었 던 두 변수간의 상호작용이 나타났으며 $(\mathrm{F}(1,144)=12.526, \mathrm{p}$ $=.001)$, 소비자의 사회적 배제 경험의 주효과 $(\mathrm{F}(1,144)=.962$, $\mathrm{p}=.330)$ 와 메시지의 소구유형의 주효과 $(\mathrm{F}(1,144)=.196$, $\mathrm{p}=.660)$ 는 통계적으로 유의하지 않아 실험 1 과 동일한 결과를 얻었다.

좀 더 구체적인 상호작용의 패턴을 확인하기 위해 대비 검 정을 실시하였다. <Table 2>에서 제시한 바와 같이 암묵적으 로 무시를 경험한 소비자의 경우, 캠페인 메시지가 자기 이익 소구일 때가 타인 이익 소구일 때보다 더 많은 금액을 기부한 반면(M타인 이익 $=9,500$ vs. $M$ 자기 이익 $=20,048 ; F(1$, $144)=4.75, p=.033)$, 거절을 경험한 소비자는 타인 이익 소구일 때가 자기 이익 소구일 때보다 더 많은 금액을 기부 하였다(M타인 이익 $=24,895$ vs. $M$ 자기 이익 = 11,333; F(1, $144)=8.00, p=.006)$. 결과적으로 가설 1 이 지지되었음을 알 수 있다.

Table 2: The interaction effect of social exclusion and appeal type of message on donation amount

\begin{tabular}{|c|c|c|c|c|c|c|c|}
\hline & \multicolumn{4}{|c|}{ appeal type of message } & \multirow{3}{*}{$F$} & \multirow{3}{*}{$\mathbf{P}$} \\
\hline & & \multicolumn{2}{|c|}{ other-benefit } & \multicolumn{2}{|c|}{ self-benefit } & & \\
\hline & & M (S.D.) & $\mathrm{n}$ & M (S.D.) & $n$ & & \\
\hline \multirow{2}{*}{$\begin{array}{c}\text { social } \\
\text { exclusion }\end{array}$} & ignore & $\begin{array}{c}9,500 \\
(11,967)\end{array}$ & 32 & $\begin{array}{c}20,048 \\
(12,167)\end{array}$ & 42 & \multirow{2}{*}{12.526} & \multirow{2}{*}{.001} \\
\hline & reject & $\begin{array}{c}24,895 \\
(20,108)\end{array}$ & 38 & $\begin{array}{c}11,333 \\
(12,107)\end{array}$ & 36 & & \\
\hline
\end{tabular}

\subsubsection{3. 추가 분석 결과}

감정에 대한 메시지 소구 유형과 사회적 배제 경험의 영향 을 분석하기 위해 각 항목에 대해 ANOVA를 실시하였다. 동정 심, 죄책감, 전반적인 부정 감정에 대한 메시지 소구 유형과 사회적 배제 경험의 주효과는 모두 통계적으로 유의하지 않았 다(p>.05). 감정에 대한 두 독립변수의 상호작용 효과 역시 통 계적으로 유의미한 결과를 보이지 않았다(p>.10). 이 결과는 소비자의 친사회적 행동에 대한 메시지 소구 유형과 사회적 배제와의 상호작용효과가 동정심이나 죄책감, 부정적 감정에 의해 나타난 결과가 아님을 보여준다.

\section{4. 결론}

\section{1. 요약 및 시사점}

본 연구는 친사회적 행동에 대한 메시지 소구 유형과 사회 적 배제 경험의 영향에 대해 살펴보았다. 이를 위해 심리학 및 마케팅 분야를 중심으로 친사회적 행동에 대한 메시지 소구 유형에 따른 효과를 설명한 기존 연구들을 제시하였으며, 사회 적 배제 경험과의 상호작용이 친사회적 행동에 영향을 미칠 것임을 예측하였다. 구체적으로 사회적으로 무시를 경험한 사 람들은 친사회적 행동을 촉구하는 캠페인의 광고에 노출되었 을 때, 타인 이익 소구보다는 자기 이익 소구 메시지에 더 호 의적인 반응을 나타내는 반면, 사회적으로 거절을 경험한 사람 들은 자기 이익 소구 메시지보다는 타인 이익 메시지에 더 긍 정적인 반응을 나타낼 것으로 예상하였다. 이러한 가설을 검증 하기 위해 두 개의 실험을 진행하였는데, 실험 1 은 지구 온난 화 방지 캠페인 광고에 노출된 상황에서 사회적 배제 경험과 메시지 소구 유형간의 관계를 살펴보았고, 실험 2에서는 아동 구제 기금 모금 캠페인을 이용하여 동일한 효과를 검증하였다. 분석 결과, 사회적으로 무시를 경험한 사람들은 메시지가 자기 이익 소구일 때가 타인 이익 소구일 때 보다 더 긍정적인 친 사회적 행동을 유발하였고, 사회적으로 거절을 경험한 사람들 은 이와 반대로 타인 이익 소구 메시지일 때가 자기 이익 소 구일때보다 더 긍정적인 반응을 보였다. 따라서 본 연구의 가 설은 지지되었으며, 이러한 발견은 다음과 같은 의미있는 시사 점을 제공할 것이다.

먼저 본 연구의 학문적 시사점을 다음과 같다. 본 연구는 친사회적 행동에 대한 메시지 소구 유형의 효과성을 조절하는 새로운 조건을 제시함으로써 친사회적 행동 관련 연구 분야를 확장했다는 점에 의의가 있다. 관련 분야의 선행연구를 살펴보 면, 친사회적 행동에 영향을 미치는 변수는 대부분 소비자의 친환경적 소비 성향이나 의사결정 상황에서 직면하게 되는 다 양한 마케팅 툴에 집중되어 있었다. 본 연구는 소비자의 사회 적 배제 경험이라는 개인적인 상황 및 조건에 따라 친사회적 행동에 대한 반응이 다르게 나타날 수 있음을 밝혔다. 특히 사 회적 배제를 사회적 무시와 사회적 거절로 구분하여 캠페인 메시지의 유형에 따라 차별화된 행동을 이끌 수 있음을 제시 하였다.

또한 본 연구는 사회적 배제 관련 문헌에도 시사점을 제공 한다. 선행연구에 따르면 친사회적 행동에 대한 사회적 배제의 영향은 혼재된 연구 결과를 보여주었다. 사회적 배제를 경험하 게되면 공격성과 반사회적 행동을 증가시키거나(Williams, Cheung, \& Choi, 2000), 부정적인 정서를 유발하여 인지적 결 핍으로 인해 반사회적 행동을 나타낸다(Baumeister, DeWall, Ciarocco, \& Twenge, 2005). 결국 사회적으로 소속되지 못하 고 배제를 경험한 사람들은 부정적인 정서 반응을 경험하게 되고, 인지적 정보처리의 감소로 인해 부정적인 행동을 하게 된다는 것이다. 하지만 이와 반대로 사회적 배제 경험이 긍정 적인 효과를 보인다는 연구결과도 다수 존재한다. 사회적 배제 는 사람들과의 재연결을 갈망하게 되는데 이는 소속감을 향상 시키는 소비를 증가시키거나(Meadet al., 2011) 사람들과의 재 결성을 위한 행동을 하려고 노력한다는 것이다(Lovelandetal, 2010). 더불어 사회적 배제가 타인에 대한 친절을 증가시키고 친 사회적 행동을 증가시키는 긍정적인 효과도 강조되어 왔다 
(Maner, Dewall, Baumeister, \& Schaller, 2007; Twenge, Baumeister, Tice, \& Stucke, 2001). 이러한 상반된 결과는 욕 구의 차이나 감정의 차이 등으로 설명되어 왔으나, 사회적 배 제에 의한 친사회적 행동에 대한 차별적 반응을 광고 메시지 의 소구 유형과의 상호작용으로 살펴본 연구는 거의 찾아볼 수 없다. 본 연구는 사회적 배제에 대한 영향이 다르게 나타날 수 있는 경계조건을 제안함으로써 선행연구를 확장하였다.

더불어 본 연구 결과는 마케팅 실무자에게 다음과 같은 실 무적 시사점을 제공한다. 먼저 캠페인 광고 메시지 -자기 혹은 타인 이익 소구 메시지-와 같이 마케팅 실무자들이 조작할 수 있는 변수를 통해 친사회적 행동을 촉구할 수 있는 커뮤니케 이션 방법을 개발할 수 있다. 예를 들어 SNS를 활용한 기부 캠페인을 하는 경우, 사람들과 재연결을 원하거나 사회적 관계 를 맺고 싶어하는 등 사회 관계에 중점을 둔 소비자에게는 타 인 중심 메시지를 노출하는 것이 더 긍정적인 행동을 유도하 는 반면, 사람들에게 자신이 누구인지 그리고 자신의 의미를 보여주고자 하는 욕구가 강한 소비자에게는 자기 중심 메시지 를 노출하는 것이 기부행동을 강화시키는데 효과적일 것이다.

\section{2. 연구의 한계점 및 향후 연구방향}

다양한 시사점에도 불구하고 본 연구는 몇 가지 한계점을 가지고 있다. 첫째, 본 연구는 소비자의 친사회적 행동에 대한 사회적 배제 경험과 메시지 소구 유형의 상호작용의 역할을 살펴보기 위해 두 개의 실험을 진행하였으며, 그 결과 가설을 지지하는 결과를 도출하였다. 하지만 이러한 효과가 왜 나타났 는지에 대한 메커니즘은 밝히지 못하였다. 선행 연구에 따르 면, 사회적 배제 유형에 따라 다른 반응이 나타나는 것은 욕구 의 차이 혹은 감정의 차이로 설명한바 있다. 하지만 이러한 요 인들은 본 연구 결과를 설명하는 메커니즘으로 작동하지 않았 음을 실험 2를 통해 살펴보았다. 따라서 사회적 배제경험과 메시지 소구 유형간의 상호작용이 친사회적 행동에 미치는 영 향이 어떠한 심리적 기제에 의해 매개되는지 향후 연구를 통 해 밝히는 것은 매우 의미있는 일일 것이다. 둘째, 본 연구의 두 개 실험의 피험자는 모두 20 대 대학생이다. 만일 일반 성 인들을 대상으로 연구를 진행한다면 본 연구 결과와 동일할 것인지 의문이 있을 수 있다. 따라서 향후 연구에서는 다양한 인구통계적 특성을 포함하는 응답자 집단으로 연구를 진행할 필요성이 제기된다. 셋째, 본 연구는 사회적 배제 조건을 피험 자의 경험을 기반으로 자유기술하는 방식으로 조작하였다. 피 험자의 주관적 경험에 의존하는 조작 방식으로 인해 사회적 배제 경험에서 느껴지는 경험의 강도와 의미는 피험자마다 다 를 수 있고 이 차이가 최종 의사결정에 다르게 영향을 미칠 수 있을 것이다. 향후 연구에서는 사회적인 배제 상황이 기술 된 시나리오를 통해 조작하는 등 다양한 방법을 사용하여 해 당 변수를 조작해 볼 필요가 있다.

\section{Reference}

Allen, C. T. (1982). Self-perception based strategies for stimulating energy conservation. Journal of Consumer Research, 8(4), 381-390.

Baek, T. H., Yoon, S., Kim, S., \& Kim, Y. (2019). Social exclusion influences on the effectiveness of altruistic versus egoistic appeals in charitable advertising. Marketing Letters, 30(1), 75-90.

Batson, C. D. (1990). How social an animal? The human capacity for caring. American Psychologist, 45(3), 336.

Baumeister, R. F., \& Leary, M. R. (1995). The need to belong: desire for interpersonal attachments as a fundamental human motivation. Psychological Bulletin, 117(3), 497-529.

Baumeister, R. F., DeWall, C. N., Ciarocco, N. J., \& Twenge, J. M. (2005). Social exclusion impairs self-regulation. Journal of Personality and Social Psychology, 88(4), 589-604.

Bendapudi, N., Singh, S. N., \& Bendapudi, V. (1996). Enhancing helping behavior: An integrative framework for promotion planning. Journal of Marketing, 60(3), 33-49.

Brunel, F. F., \& Nelson, M. R. (2000). Explaining gendered responses to "help-self" and "help-others" charity ad appeals: The mediating role of world-views. Journal of Advertising, 29(3), 15-28.

Buckley, K. E., Winkel, R. E., \& Leary, M. R. (2004). Reactions to acceptance and rejection: Effects of level and sequence of relational evaluation. Journal of Experimental Social Psychology, 40(1), 14-28.

Cacioppo, J. T., Chen, H. Y., \& Cacioppo, S. (2017). Reciprocal influences between loneliness and self-centeredness: A cross-lagged panel analysis in a population-based sample of African American, Hispanic, and Caucasian adults. Personality and Social Psychology Bulletin, 43(8), 1125-1135.

Cheung, E. O., \& Gardner, W. L. (2015). The way I make you feel: Social exclusion enhances the ability to manage others' emotions. Journal of Experimental Social Psychology, 60, 59-75.

Cialdini, R. B., Brown, S. L., Lewis, B. P., Luce, C., \& Neuberg, S. L. (1997). Reinterpreting the empathyaltruism relationship: When one into one equals oneness. Journal of personality and social psychology, 73(3), 481-494.

De Groot, J. I., \& Steg, L. (2008). Value orientations to explain beliefs related to environmental significant behavior: How to measure egoistic, altruistic, and biospheric value orientations. Environment and Behavior, 40(3), 330-354.

DeBono, A. E. (2011). Why am I left out? Interpretations of exclusion affect anti-social and pro-social behaviors. State University of New York at Albany.

DeWall, C. N., \& Baumeister, R. F. (2006). Alone but feeling no pain: Effects of social exclusion on physical pain tolerance and pain threshold, affective forecasting, and interpersonal empathy. Journal of Personality and Social Psychology, 91(1), 1-54.

Dovidio, J. F., Allen, J. L., \& Schroeder, D. A. (1990). Specificity of empathy-induced helping: Evidence for 
altruistic motivation. Journal of Personality and Social Psychology, 59(2), 249-260.

Fisher, R. J., Vandenbosch, M., \& Antia, K. D. (2008). An empathy-helping perspective on consumers' responses to fund-raising appeals. Journal of Consumer Research, 35(3), 519-531.

Gardner, W. L., Pickett, C. L., \& Brewer, M. B. (2000). Social exclusion and selective memory: How the need to belong influences memory for social events. Personality and Social Psychology Bulletin, 26(4), 486-496.

Griskevicius, V., Tybur, J. M., \& Van den Bergh, B. (2010). Going green to be seen: status, reputation, and conspicuous conservation. Journal of Personality and Social Psychology, 98(3), 392-404.

Hess, Y. D., \& Pickett, C. L. (2010). Social rejection and self-versus other-awareness. Journal of Experimental Social Psychology, 46(2), 453-456.

Holmes, J. G., Miller, D. T., \& Lerner, M. J. (2002). Committing altruism under the cloak of self-interest: The exchange fiction. Journal of Experimental Social Psychology, 38(2), 144-151.

Kemp, E., Moore, D. J., \& Cowart, K. (2016). Me, myself, and I: examining the effect of loneliness and self-focus on message referents. Journal of Current Issues \& Research in Advertising, 37(1), 15-27.

Knowles, M. L. (2014). Social rejection increases perspective taking. Journal of Experimental Social Psychology, 55, 126-132.

Lakin, J. L., Chartrand, T. L., \& Arkin, R. M. (2008). I am too just like you: Nonconscious mimicry as an automatic behavioral response to social exclusion. Psychological Science, 19(8), 816-822.

Lee, J., \& Shrum, L. J. (2012). Conspicuous consumption versus charitable behavior in response to social exclusion: A differential needs explanation. Journal of Consumer Research, 39(3), 530-544.

Loveland, K. E., Smeesters, D., \& Mandel, N. (2010). Still preoccupied with 1995: The need to belong and preference for nostalgic products. Journal of Consumer Research, 37(3), 393-408.

Luchs, M. G., Naylor, R. W., Irwin, J. R., \& Raghunathan, R. (2010). The sustainability liability: Potential negative effects of ethicality on product preference. Journal of Marketing, 74(5), 18-31.

Maner, J. K., DeWall, C. N., Baumeister, R. F., \& Schaller, M. (2007). Does social exclusion motivate interpersonal reconnection? Resolving the" porcupine problem." Journal of Personality and Social Psychology, 92(1), 42-55.

Mathur, A. (1996). Older adults' motivations for gift giving to charitable organizations: An exchange theory perspective. Psychology \& Marketing, 13(1), 107-123.

Mead, N. L., Baumeister, R. F., Stillman, T. F., Rawn, C. D., \& Vohs, K. D. (2010). Social exclusion causes people to spend and consume strategically in the service of affiliation. Journal of Consumer Research, 37(5), 902-919.

Molden, D. C., Lucas, G. M., Gardner, W. L., Dean, K., \& Knowles, M. L. (2009). Motivations for prevention or promotion following social exclusion: Being rejected versus being ignored. Journal of Personality and Social Psychology, 96(2), 415-431.

Oh, M. J. \& Hwang, Y. (2014). Does social exclusion decrease ethical consumption behavior?. Journal of Consumer Studies, 25(4), 181-203.

Oh, M. J., Park, K. K., \& Park, J. C. (2017). Will Hedonic Products Appeal to Social Exclusion?. Journal of Cultural Industry Studies, 17(3), 55-63.

Peattie, K. (2001). Towards sustainability: the third age of green marketing. The Marketing Review, 2(2), 129-146.

Peattie, K., \& Crane, A. (2005). Green marketing: legend, myth, farce or prophesy?. Qualitative Market Research: an International Journal, 8(4), 357-370.

Son, J. S. \& Lee, B. K. (2016). The effects of social exclusion and recipient's facial expression on consumer responses to public service advertisement: Focused on Duchenne smile and sad face. The Korean Journal of Consumer and Advertising Psychology, 17(2), 357-374.

Stephens, N., \&Gwinner, K. P. (1998). Why don't some people complain? A cognitive-emotive process model of consumer complaint behavior. Journal of the Academy of Marketing Science, 26(3), 172-189.

Stern, P. C. (2000). New environmental theories: toward a coherent theory of environmentally significant behavior. Journal of Social Issues, 56(3), 407-424.

Taylor, S., \& Todd, P. (1995). An integrated model of waste management behavior: A test of household recycling and composting intentions. Environment and Behavior, 27(5), 603-630.

Twenge, J. M., Baumeister, R. F., Tice, D. M., \& Stucke, T. S. (2001). If you can't join them, beat them: Effects of social exclusion on aggressive behavior. Journal of Personality and Social Psychology, 81(6), 1058-1069.

Warburton, W. A., Williams, K. D., \& Cairns, D. R. (2006). When ostracism leads to aggression: The moderating effects of control deprivation. Journal of Experimental Social Psychology, 42(2), 213-220.

Webb, D. J., Mohr, L. A., \& Harris, K. E. (2008). A re-examination of socially responsible consumption and its measurement. Journal of Business Research, 61(2), 91-98.

Westbrook, R. A. (1980). Intrapersonal affective influences on consumer satisfaction with products. Journal of Consumer Research, 7(1), 49-54.

White, K., \& Peloza, J. (2009). Self-benefit versus other-benefit marketing appeals: Their effectiveness in generating charitable support. Journal of Marketing, 73(4), 109-124.

Williams, K. D., Cheung, C. K., \& Choi, W. (2000). 
Cyberostracism: effects of being ignored over the Internet. Journal of Personality and Social Psychology, 79(5), 748-762.

Zeelenberg, M., \&Pieters, R. (2004). Beyond valence in customer dissatisfaction: A review and new findings on behavioral responses to regret and disappointment in failed services. Journal of business Research, 57(4), 445-455. 